\title{
DOE/ER/40763.. TI
}

TECHNICAL REPORT

for the year 1994

on

\section{ADVANCED MATERIALS, STRANDS, AND CONDUCTORS}

FOR

PARTICLE ACCELERATORS

to the

Advanced Technology Research and Development Branch

Division of High Energy physics

U.S. Department of Energy

Washington, DC 20585

\section{BATTELLE}

505 King Ave

Columbus, OH 43201

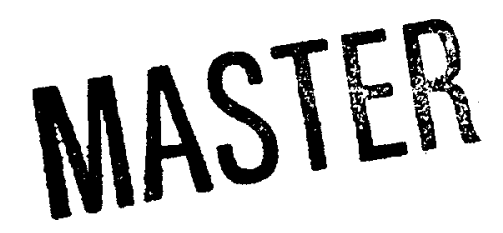

September 6, 1994 


\section{DISCLAIMER}

Portions of this document may be illegible in electronic image products. Images are produced from the best available original document. 


\section{TECHNICAL REPORT \\ for the year 1994 \\ on}

ADVANCED MATERIALS, STRANDS, AND CONDUCTORS

FOR

\section{PARTICLE ACCELERATORS}

to the

Advanced Technology Research and Development Branch

Division of High Energy physics

U.S. Department of Energy

Washington, DC 20585

from

BATTELLE

505 King Ave

Columbus, OH 43201

September 6, 1994

\section{INTRODUCTION RESEARCH PROPOSED FOR THE PERIOD 1994-1996}

A research program on advanced materials, strands, and conductors, to be performed during the three-year period 1994-1996 was proposed in August 1993. Although founded firmly on our own research the proposed program was based on discussions and other types of contact that we have had with the HEP community. Six tasks were originally proposed, and three were accepted. The tasks accepted for accomplishment during the period 1994-1996 are listed below:

\section{Task-A: Metallurgical and Electrical Bridging in Multifilamentary $\mathrm{Nb}_{3} \mathrm{Sn}$ Strands}

A problem of considerable current importance in $\mathrm{Nb}_{3} \mathrm{Sn}$ multifilamentary (MF) strand processing concerns the effective enlargement of the filaments by bridging. Discussions at recent magnet- and high-field workshops tend to suggest that, as static magnetic phenomena, bridging and proximity effect have certain formal similarities (e.g. in functional form of their per-cycle hysteretic loss versus sample length). Furthermore, the workshop discussions and the recent literature seem to indicate that, from a mechanistic standpoint, bridging consists of two components: (1) metallurgical bridging and (2) electrical proximity effect (PE) -- and not just in special-purpose strands (cf. fine-filament NbTi) but in strands of present practical interest. The relative importances of these two components needs to be examined. With our experience with proximity effect coupling in multifilamentary $\mathrm{NbTi}$, we are well positioned to study bridging-type coupling phenomena. 
Task-B: Advanced NbTi Filamentary Strands: Influence of Filament Quality and Coatings and Innovative Matrices on Static and Dynamic Interfilamentary Coupling

With regard to NbTi-based multifilamentary strands, although most of the standard problems have been solved, industry and user groups still maintain considerable interest in advanced strands for high field-ramp-rate applications. Accordingly, in collaboration with industry, who will provide materials for study, we have planned a program to address: (1) questions associated with fine filaments for special high-dB/dt applications; (2) process improvements to increase filament quality (reduce asperities) and hence reduce mechanically induced interfilamentary coupling; (3) alternative filament coatings (filament-surface barriers) which while they perform their traditional function (resisting surface-compound formation) also assist in reducing both proximity-effect- and eddy-current interfilamentary coupling; (4) the design of innovative matrices engineered to control both proximity effect- and eddy-current coupling and that, by the diffusion of whose solute, can also provide a useful barrier at the filament/matrix interface -- what might be termed "in-situ filament coating".

\section{Task-C: Cables, Strand Coatings, Interstrand Contact Resistance, and Cable Properties}

Cable and strand eddy current loss studies abound. However, refinement of our ideas about magnetization and loss are needed, since the next generation of high-field dipoles are likely to be even more stringent in their requirements, regardless of the superconductive materials used. Most cable loss models, in order to simplify the problem, make certain assumptions about the way in which the strands behave in the cable. In particular, cables are treated as a resistance network, with certain fixed resistances between neighboring strands (but see below). Additionally, matrix resistivity (transverse and longitudinal), shell resistivity, and contact resistance are lumped into an overall interstrand resistance $\left(\mathrm{R}_{\mathrm{is}}\right)$. This approach is fine for fitting the results of calculations to existing cables, but is inadequate for the design of cables for use in future magnets. Accurate information about the contributions of contact resistance, various strands coatings, inner barriers, and matrix resistivity to the overall $R_{\text {is }}$ are needed. Additionally, modelling which uses a more detailed model of strand behavior would be helpful. We plan to study these issues in order to provide information which will be of use in the development of the next generation of high-field dipole magnets. 
RESEARCH PROGRESS AS OF AUGUST, 1994

\section{TASK-A: METALLURGICAL AND ELECTRICAL BRIDGING IN

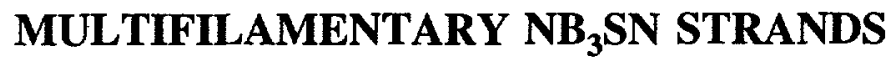

\section{Theoretical Studies}

During 1994 Battelle has been developing theory to describe loss in $\mathrm{Nb}_{3} \mathrm{Sn}$ strands with bridging. This theory describes the effects of external strand parameters; twist pitch $\left(\mathrm{L}_{\mathrm{p}}\right)$, sample length $(\mathrm{L})$, and strand diameter $\left(\mathrm{d}_{\mathrm{s}}\right)$. Additionally, a parameter is extracted which should correlate with the level of optically observable bridging. This connection will be tested when IGCproduced samples become available (see below).

Our main goals in the pursuit of this research are: (1) To develop measurement and theory to the point where measurements between different samples can be quantitatively compared. This has been done by developing a description of an intrinsic level of bridging--a parameter that is not dependent on external strand parameters. (2) To correlate the coupling present in the strands with results from microscopy, and in so doing, aim to illuminate the particulars of the bridging mechanism. (3) To develop methods to minimize mechanical bridging or its effects.

Based on the above, a theoretical paper is being prepared for submission to the journal Cryogenics

\section{Experimental Studies}

For sample materials for measurement we rely on outside suppliers. Accordingly we have held discussions with IGC-ASI on the subject of bridging in $\mathrm{Nb}_{3} \mathrm{Sn}$. The first experimental studies will be performed on several $\mathrm{Nb}_{3} \mathrm{Sn}$ composite strands that have been subjected to various heat treatments. Corresponding to each heat treatment condition we will prepare a set of samples with lengths varying from about $2 \mathrm{~mm}$ up to about $10 \mathrm{~mm}$.

Vibrating-sample magnetometry will be performed. Excess magnetization due to bridging will be interpreted in terms of bridging critical current density. In this way we hope to establish a quantitative measure of the extent of bridging. Measurements will begin as soon as the samples become available.

The work will continue into 1995 and beyond as samples with various solute additions to both the superconductor and the matrix become available. 


\section{TASK-B: ADVANCED NbTi FILAMENTARY STRANDS: INFLUENCE OF FILAMENT QUALITY AND COATINGS AND INNOVATIVE MATRICES ON STATIC AND DYNAMIC INTERFILAMENTARY COUPLING}

Static interfilamentary coupling refers to proximity effect coupling, which always shows up if the filaments are sufficiently fine (closely packed at the usual s/d ratios). Filament "quality" may also play a role -- static coupling could also result from some kind of direct- or proximity-enhanced metallurgical bridging (see Task A). Dynamic coupling refers to eddy current coupling.

Research materials consisted of strands supplied by the VAMAS Technical Working Party office, augmented by some research alloys that had been separately melted for study as potential matrix materials. So far our work has focussed on static coupling and the influence of: (i) matrix properties (resistivity, magnetic susceptibility) and (ii) filament coatings on it.

\section{Matrix Properties}

Based on measurements on VAMAS-supplied strands, augmented by our own and published data, we have compared the PE-suppression strengths of $\mathrm{Cu}-\mathrm{Ni}$, $\mathrm{Cu}-\mathrm{Mn}, \mathrm{Cu}-\mathrm{Ni}-\mathrm{Mn}$, and $\mathrm{Cu}-\mathrm{Si}$ matrices. The results of this work, now completed, has been submitted for publication in Cryogenics article entitled "Anomalous Magnetic Properties and Proximity Effect Coupling in VAMAS Strands". We have also looked at the magnetic properties of $\mathrm{Cu}-\mathrm{Mn}, \mathrm{Cu}-\mathrm{Ni}$, and $\mathrm{Cu}-\mathrm{Ni}-\mathrm{Mn}$ at concentrations most likely to be used for accelerator strands. The results of this work have been submitted to J. Appl. Phys. under the title "Influence of Ni Additions on the Low Temperature Magnetic Properties of a Cu-1\%Mn Strand".

\section{Filament Coatings}

The possible role of $\mathrm{Nb}$ coatings (or filament/matrix reaction barriers) in promoting PE coupling between filaments was forced to our attention during an evaluation of the $2^{\text {nd }}$ VAMAS Round Robin test results. The $\mathrm{Cu}$-matrix VAMAS strands had a much lower level of PE coupling than did any USmanufactured $\mathrm{Cu}$-matrix strand that we have measured. In fact from a PEcoupling standpoint the VAMAS strands (of Japanese manufacture) were equivalent to US-made $\mathrm{Cu}-0.5 \mathrm{Mn}$-matrix strands. We initially though that this 
had to do with filament quality -- the VAMAS strands having been cold extruded

while the US strands had been hot extruded. However, further enquiry revealed another important difference: the VAMAS strands did not employ a $\mathrm{Nb}$ barrier around the filaments. This issue is discussed in a paper ready for submission to Cryogenics under the heading "Second VAMAS Round-Robin Testing of Two Classes of NbTi Multifilamentary Strand -- Magnetization Measurement of Low-Frequency AC Loss".

We intend to continue examining the barrier and filament quality issues. We plan to measure the magnetizations of strands, manufactured by similar procedures: (i) both with and without $\mathrm{Nb}$ barriers, (ii) both with and without $\mathrm{Si}$ in the matrix. Of course we will continue to remain alert to the possible effects of differences in filament quality. On the theoretical side we intend to look at the influence of a $\mathrm{Nb}$ interlayer on $\mathrm{PE}$ coupling between $\mathrm{NbTi}$ and $\mathrm{Cu}$.

\section{TASK-C: CABLES, STRAND COATINGS, INTERSTRAND CONTACT RESISTANCE, AND CABLE PROPERTIES}

During 1994 the largest fraction of our effort has been devoted to the study of strand coatings, interface contact resistance ("transconductance"), and the eddy current component of $\mathrm{AC}$ loss in cables. Both NbTi- and $\mathrm{Nb}_{3} \mathrm{Sn}$-based cables are covered under this Task. The focus of the ongoing research is on strand coatings are their properties. To ensure both the technical success of this Task and its relevance to the needs of the High Energy Physics community, strong collaborative ties are being maintained with Lawrence Berkeley Laboratory (LBL). Relationships with the cable people both at the University of Twente, Enschede, Netherlands, and the Japanese High Energy Physics Laboratory (KEK), Tsukuba, have also been established.

\section{NbTi-Base Cables}

Under this heading we are studying the low-frequency eddy current loss in Rutherford cables would from multifilamentary SSC-type strands to which have been applied thin electroplated or electrolessly plated coatings of metals, alloys and oxides. Sample materials acquisition for this study began in 1993. 


\section{Strand Coating}

Two 2,000 ft spools of an older SSC-type strand (manufactured by IGC) were obtained from LBL through the courtesy of Drs C. E. Taylor and R. M. Scanlan. Segments of this strand (several hundred feet or more in length) were submitted to several vendors who applied insulating- or resistive-metallic coatings using either electroless or electrolytic techniques. MacDermid Inc used the electroless method to apply coatings of: (a) red copper oxide, (b) black copper oxide, (c) amorphous (hence nonmagnetic) Ni-P(9-11\%) alloy, (d) crystalline $\mathrm{Ni}-\mathrm{Fe}(10 \%)$ alloy to $230 \mathrm{ft}$ lengths of strand. Hudson International electroplated about $2000 \mathrm{ft}$ of strand with pure Ni. Hard Chrome Consultants electroplated $330 \mathrm{ft}$ lengths of strand with (a) two thicknesses of pure $\mathrm{Cr}$, (b) pure $\mathrm{Ni}$ (c) pure $\mathrm{Ni}$ overlaid with pure $\mathrm{Cr}$. The metallic single-layers were about $2-4 \mu \mathrm{m}$ in thickness. Altogether, nine plated strands were prepared for cabling.

\section{Cable Winding}

Arrangements were made with LBL to have the seven types of coated strand wound into miniature 12-strand Rutherford cables. To enable this to be carried out in a single cabling operation the following steps were taken: Each coated strand was subdivided into twelve equal lengths. A variegated length of strand was made by welding end-to-end one piece of each of the plated strands interspersed with, and topped and tailed with, lengths of uncoated strands for the purposes of handling and demarkation. This was repeated twelve times; the resulting variegated strands were then wound onto twelve spools in preparation for cabling. The result of the cabling process was a single length of 12-strand cable made up of alternating plated and unplated zones. The 10zone (including plated and unplated zones) cable was subsequently cut up into lengths suitable for AC loss measurement.

\section{Interstrand Contact Resistance and AC Loss}

(a) Interstrand Contact Resistance: A fixture was designed and constructed for measuring directly the interstrand contact resistance under variable loading. A low-frequency- AC four-terminal technique will be employed. Some testing has been done but no actual resistance measurements have yet been performed. Measurements may begin in 1994 and continue into 1995.

(b) Screening Studies: A screening test, that is intermediate between a contact resistance measurement and an AC-loss cable measurement has been 
devised. The idea is to prepare a rectangular arrangement of four lengths of strand and place them under pressure. A time-varying field will then cause an eddy current to flow around the rectangle and across the four interstrand contacts. A fixture has been designed and constructed to enable this test to be carried out in a vibrating sample magnetometer (VSM). From a qualitative standpoint this experiment will enable the loss-suppressing effectiveness of various coatings to be evaluated in terms of the hysteretic loss of the strand, which is known. Quantatively, from the geometry of the arrangement and the rate of change of the applied field the actual contact resistance can be calculated from the measured eddy current magnetization. Measurements are planned for September and October, 1994. They will continue into 1995 as more plated strands become available.

(c) VSM Measurements of AC Loss: A fixture has been designed and constructed to facilitate the VSM measurement of AC loss in short lengths of cable under pressure. Preliminary tests indicated that the apparatus possessed sufficient sensitivity to enable the hysteretic and eddy current components of $\mathrm{AC}$ loss to be clearly separated. The first experiments were performed on aswound (not annealed) bare cable. Experiments continuing into 1995 will investigate the combined effects of annealing and applied pressure in the AC loss.

(c) Calorimetric Measurements of AC Loss: Calorimetric measurements of blocks of coated cables (plus one uncoated cable) were made at the University of Twente, Enschede, Netherlands. In preparation for measurement the cable stacks were heat treated for $2 \mathrm{~h} / 160^{\circ} \mathrm{C}$ under a pressure of $25 \mathrm{MPa}$. They were subsequently measured under pressures of up to $100 \mathrm{MPa}$. The results of these measurements are being prepared for presentation at the Applied Superconductivity Conference. Further tests are planned in which more aggressive pre-measurement heat treatments will be applied. These measurements are planned for 1995.

\section{$\mathrm{Nb}_{3} \mathrm{Sn}$-Base Cables}

To produce the higher field dipoles needed for the next generation of accelerators (or accelerator upgrades) cabled conductor would from $\mathrm{Nb}_{3} \mathrm{Sn}$-base multifilamentary composite strands will be needed. The brittleness of $\mathrm{Nb}_{3} \mathrm{Sn}$ requires the use of the wind-and-react method of magnet manufacture. 


\section{$\mathrm{Cr}$ as a Sintering Barrier}

To prevent macroscopic interstrand bridging from taking place during reaction heat treatment at temperatures of $650-700^{\circ} \mathrm{C}$ a refractory diffusion barrier of some kind must be applied to the surface of the strand. Electroplated $\mathrm{Cr}$ is the coating of choice, although some cables have been heat treated after exposure to a suitable grade of mineral oil. The residual resistance ratio, RRR (expressed in terms of a $20 \mathrm{~K}$ relative resistance, $\mathrm{RR}$ ) of the $\mathrm{Cr}$-plated $\mathrm{Nb}_{3} \mathrm{Sn}$ composite strand becomes seriously degraded during the reaction heat treatment. The degradation seems to be a result of $\mathrm{Cr}$ diffusion, in spite of the low solubility and diffusivity of $\mathrm{Cr}$ in $\mathrm{Cu}$ at the temperatures of interest. Although the presence of $\mathrm{Cr}$ on the outside of RR-degraded strands was seen as a strong empirical correlation, until recently, some questions still remained about the origin of the degradation. Our work in helping to confirm that $\mathrm{Cr}$ (with the aid of oxygen diffusion, which acts to enhance RR in unplated strands) is indeed the cause of the difference in RRR for plated and unplated strands is detailed in the ASC presentation, as well as articles intended for submission to J. Appl. Phys. and Cryogenics.

Experiments are still under way to explore the extent of the RR degradation and to recommend ways of: (a) minimizing the RR degradation or (b) recovery some of the lost RR by post-heat-treatment aging. It is expected that aging studies may continue into 1995 .

\section{Cr as an Eddy Current Barrier}

A secondary role of the $\mathrm{Cr}$ coating is as a barrier to inhibit interstrand eddy current generation in a time-dependent applied magnetic field. Other refractory coatings may also serve as eddy current barriers. In this regard, during 1995, some thought will be given to alternative strand design that combine RR preservation with eddy current inhibition. 


\section{PUBLICATION OF OF RESEARCH RESULTS}

Credited to

U.S. Department of Energy

Division of High Energy Physics

Grant No. DE-FG02-93ER40763

\section{PAPERS THAT APPEARED IN PRESS IN THE YEAR 1994}

Properties of the Superconductor (NbTi)

1. MAGNETIC SUSCEPTIBILITY STUDIES OF THE INFLUENCES OF THERMOMECHANICAL PROCESSING AND Mn ADDITION ON PHASE STABILITY AND PRECIPITATION IN NbTi ALLOYS

D. S. PYUN, R. D. SMITH, and E. W. COLLINGS, Advances in Cryogenic Engineering (Materials) 40, 831-838 (1994).

2. INFLUENCE OF MANGANESE ON THE UPPER CRITICAL FIELD OF TWO SERIES OF $\beta$-QUENCHED- AND PRECIPITATION-HEAT TREATED NbTi ALLOYS, D. S. PYUN and E. W. COLLINGS, Advances in Cryogenic Engineering (Materials) 40, 717-724 (1994).

Properties of the Strand

3. FIELD AND LENGTH DEPENDENCE OF THE CREEP RATE IN PROXIMITY EFFECTED MULTIFILAMENTARY STRANDS,

M. D. SUMPTION and E. W. COLLINGS, Advances in Cryogenic Engineering (Materials) 40, 799-806 (1994).

4. LONGITUDINAL COMPONENT RESISTIVITIES OF MULTIFILAMENTARY COMPOSITE STRANDS -- INFLUENCE OF SIZE EFFECT AND FILAMENTARY INTERDIFFUSION D. S. PYUN and E. W. COLLINGS, Advances in Cryogenic Engineering (Materials) 40, 815-822 (1994). 
5. TRANSVERSE RESISTIVITIES OF Cu-MATRIX AND $\mathrm{Cu}-\mathrm{Mn}$ MATRIX MULTIFILAMENTARY STRANDS AS FUNCTIONS OF MAGNETIC FIELD AND TEMPERATURE,

M. D. SUMPTION, and E. W. COLLINGS, Advances in Cryogenic Engineering (Materials) 40, 807-814 (1994).

\section{Properties of the Cable}

6. INFLUENCE OF CABLE AND TWIST PITCH INTERACTIONS ON EDDY CURRENTS IN MULTIFLLAMENTARY STRANDS CALCULATED USING AN ANISOTROPIC CONTINUUM MODEL, M. D. SUMPTION and E. W. COLLINGS, Advances in Cryogenic Engineering (Materials) 40, 579-587 (1994).

7. INFLUENCE OF TWIST-PITCH AND SAMPLE LENGTH ON PROXIMITY EFFECT COUPLING IN MULTIFILAMENTARY COMPOSITES DESCRIBED IN TERMS OF A FIELDINDEPENDENT, TWO-CURRENT-REGION MODEL, M. D. SUMPTION AND E. W. COLLINGS, Cryogenics 34, 491-505 (1994).

\section{PAPERS THAT WERE SUBMITTED FOR PUBLICATION} IN THE YEAR 1994

8. CREEP IN SUPERCONDUCTIVE COMPOSITES WITH ANISOTROPIC PINNING POTENTIALS

M. D. SUMPTION AND E. W. COLLINGS, J. Appl. Phys. -- accepted for publication.

9. INFLUENCE OF Ni ADDITIONS ON THE LOW TEMPERATURE MAGNETIC PROPERTIES OF A Cu-1\%Mn ALLOY

M. D. SUMPTION AND E. W. COLLINGS, J. Appl. Phys. -submitted for publication.

III ABSTRACTS OF PAPERS THAT ARE PRESENTLY BEING PREPARED FOR SUBMISSION IN 1994 


\section{(a) FOR THE APPLIED SUPERCONDUCTIVITY CONFERENCE (ASC)}

1994: Paper No. 10

VSM and Calorimetric and Studies of Interstrand Coupling Loss in Cables under Pressure Wound from Strands with Various Coatings, M.D. SUMPTION*, E.W. COLLINGS*, Battelle, Columbus, OH, USA, R.M. SCANLAN, LBL, Berkeley, CA, USA, and H.H.J. TEN KATE, University of Twente, Enschede, ND -- The use of strand coatings for minimizing $\mathrm{AC}$ loss and coupling-induced field errors in accelerator dipoles has been investigated. AC loss was measured magnetically and calorimetrically on six different 11-strand Rutherford cables wound with strands thinly coated electrolytically with: (1) $\mathrm{Ni}$, (2) $\mathrm{Cr}$, (3) $\mathrm{Ni}+\mathrm{Cr}$, and electrolessly with: (4) Ni-P, (5) Ni-Fe, and (6) black $\mathrm{CuO}$. A bare reference cable was also measured. The multi-cable samples were blocks $0.7-0.9 \mathrm{~cm} \times 2.0 \mathrm{~cm} \times 32-40 \mathrm{~cm}$. The AC loss was measured at $100 \mathrm{MPa}$ (as well as 0,25 and 50 $\mathrm{MPa}$ in the case of the bare reference) in applied fields of 300 $\mathrm{mT}$ and $100 \mathrm{mT}$ at field sweep rates of $0.05-0.5 \mathrm{~Hz}$ and $0.5-$ $5.0 \mathrm{~Hz}$, respectively. Relaxation times extracted from the data, as well as the raw data themselves, are presented and compared. Significant eddy-current-coupling loss suppression is seen for a number of coatings.

1994: Paper No. 11

Degradation of Residual Resistance due to Chromium Diffusion into Plated $\mathbf{N b}_{\mathbf{3}} \mathbf{S n}$ Strands*, M.D. SUMPTION and E.W. COLLINGS, Battelle, Columbus, OH, USA -- The resistance ratios, $R R=R_{273 K} / R_{T}(T=20$ and $25 K)$ of various Cr-plated and unplated heat treated $\mathrm{Nb}_{3} \mathrm{Sn}$ multifilamentary strands have been compared. The degradation in $\mathrm{RR}_{\mathrm{Cr} \text {-plated }}$ has been quantitatively interpreted in terms of $\mathrm{Cr}$ diffusion. The effect of this diffusion on strand stability is considered. Taking for example a simple bimetallic model it is pointed out that the addition of an outer resistive layer to a strand will degrade its measured average RR without influencing its stability. Next, using the known diffusivity of $\mathrm{Cr}$ in $\mathrm{Cu}$, a "local" $\mathrm{RR}, \mathrm{RR}_{\text {local }}(\mathrm{x})$, is computed as function of depth $(x)$ into a stabilizer of thickness $t$ and compared with $R R_{a v}(t)$, the thickness-dependent average RR. It is shown that although $R R_{a v}(t)$ recovers rather slowly with increase of $t, R_{\text {local }}(x)$ rises very rapidly within small values of $\mathrm{x}$. This graded-medium 
analysis indicates that when diffusion into the surface is in question the average parameter is not a reliable stability criterion and in fact leads to an overestimate of diffusion-induced stability degradation.

1994: Paper No. 12

Nickel-Copper Alloys for Magnetic Compensation in Superconducting Strands*, E.W. COLLINGS and M.D. SUMPTION, Battelle, Columbus, OH, USA -- In precision-field superconducting magnets, magnetization of the windings tends to distort the design field especially in the low-field regime. The effect of winding magnetization can be canceled by the introduction of ferromagnetic components $(\mathrm{Fe}$ or $\mathrm{Ni})$ into the either the magnet structure or the strands themselves. The processing of $\mathrm{Ni}$-electroplated or $\mathrm{Ni}$ filament-substituted strands has been demonstrated and the satisfactory performance of such strands in magnets has been computer-modelled. But both the design of compensated magnets and their low-field performance could be improved by reducing $\mathrm{H}_{\mathrm{A} \text {,sat }}$, the applied field needed to saturate the ferromagnetic components. Since $\mathrm{H}_{\mathrm{A} \text {,sat }}=\mathrm{H}_{\text {sat }}+\mathrm{N}_{\mathrm{d}} \mathrm{M}_{\text {sat }}$ where $\mathrm{H}_{\text {sat }}$ is the "true" saturation field, $N_{d}$ is the demagnetization factor, and $M_{\text {sat }}$ is the saturation magnetization, the needed lowering of $\mathrm{H}_{\mathrm{A}, \text { sat }}$ can be obtained by reducing $\mathrm{M}_{\mathrm{sat}}$. The desired result can be obtained by alloying the $\mathrm{Ni}$ with $\mathrm{Cu}$-- which reduces $\mathrm{M}_{\text {sat,NiCu}}$ linearly to zero at a composition of about 60 at.\% Cu. Various ways of introducing $\mathrm{Ni}-\mathrm{Cu}$ into the strand are discussed.

1994: Paper No. 13

VAMAS Round-Robin Testing of Two Classes of NbTi Multifilamentary Strand -- Magnetization Measurement of LowFrequency AC (Hysteretic) Loss, E.W. COLLINGS*, M.D. SUMPTION*, Battelle, Columbus, OH, USA, K. ITOH. and H. WADA, NRIM, Tsukuba, Ibaraki, JN -- We report on the results of the VAMAS-sponsored round-robin low-frequency AC (hysteretic-) loss testing of two sets of multifilamentary NbTi strands (Set No. 1: Cu matrix, fil. diams. 0.5, 1, 3, and $12 \mu \mathrm{m}$; Set No. 2: mixed matrix, fil. diams. $0.4,0.5$, and $1 \mu \mathrm{m}$ ). In an initial series of tests, samples in various forms (e.g. wire bundles, coils) were measured either by vibrating-sample- or SQUID magnetometry. Considerable scatter was noted especially in the small-filament-diameter AC-loss data. A second series of tests compared the results of VSM measurement only of just the finest-filament pair of samples $(\mathrm{Cu}$ matrix and mixed matrix, respectively). In the light of all the results, factors contributing to AC loss error are discussed and 
recommendations are made concerning the specification of future round-robin AC-loss testing.

(b) FOR SUBMISSION TO JOURNALS SUCH AS CRYOGENICS, JAP, etc

\title{
1994: Paper No. 14
}

\author{
SECOND VAMAS ROUND-ROBIN TESTING OF TWO CLASSES OF NbTi \\ MULTIFILAMENTARY STRAND -- MAGNETIZATION MEASUREMENT OF LOW- \\ FREQUENCY (HYSTERETIC) AC LOSS \\ E. W. Collings ${ }^{1}$, M. D. Sumption ${ }^{1}$, K. Itoh ${ }^{2}$, H. Wada ${ }^{2}$, K. Tachikawa ${ }^{3}$, H. W. Weber ${ }^{4}$, S. \\ Zannella $^{5}$, P. Gilson ${ }^{6}$, K. Aihara ${ }^{7}$, E. S. Yoneda ${ }^{8}$, W. Steiner ${ }^{9}$, J. McKinnell ${ }^{10}$, M. Siddall ${ }^{10}$, \\ and $M$. Thöner ${ }^{11}$ \\ 1 Battelle Memorial Institute, Columbus, OH, USA \\ 2 National Research Institute for Metals, Tsukuba, Japan \\ 3 Tokai University, Hiratsuka, Japan \\ 4 Atominstitut der Österreichischen Universitäten, Vienna, Austria \\ 5 CISE spa, Milan, Italy \\ 6 C.R.E. ENEA, Frascati (Rome), Italy \\ 7. Hitachi Research Laboratory, Hitachi, Japan \\ 8 Toshiba R\&D Center, Kawasaki, Japan \\ 9 Technische Universität Wien, Vienna, Austria \\ 10 Teledyne Wah Chang Albany, Albany, USA \\ 11 Vacuumschmelze GmbH, Hanau, Germany
}

Abstract -- We report on the results of the $2^{\text {nd }}$ VAMAS intercomparison program on lowfrequency (hysteretic) AC loss measurements. Two sets of multifilamentary $\mathrm{NbTi}$ strands (Set No. 1: copper matrix, fil. diams. 0.5, 1, 3, and $12 \mu \mathrm{m}$; Set No. 2: cupronickel matrix, fil. diams. $0.4,0.5$, and $1 \mu \mathrm{m}$ ) were subjected to round-robin testing. In an initial series of tests, samples in various forms (e.g. wire bundles, coils) were measured mostly by vibratingsample- and SQUID magnetometry. Considerable scatter was noted especially in the smallfilament-diameter AC-loss data. In a study of measurement accuracy, a supplementary roundrobin series of tests compared the results of VSM measurement of a given pair of coppermatrix samples. In the light of all the results, factors contributing to AC loss error are discussed and recommendations are made concerning the specification of future round-robin AC-loss testing.

\section{4: Paper No. 15}

\section{Resistance Ratio Degradation in Chromium-Plated $\mathrm{Nb}_{3} \mathrm{Sn}$ Multifilamentary} Strands Viewed as a Diffusion Phenomenon

M. D. Sumption and E. W. Collings

Abstract: Residual resistivity ratio (RRR) degradation in $\mathrm{Cr}$ plated $\mathrm{Nb}_{3} \mathrm{Sn}$ superconducting multifilamentary strands has been investigated. Residual resistivity (RR) has been measured in representatives of two strand designs; (i) Single Barrier (SB) strands, where a central filamentary bundle is surrounded by a Ta barrier followed by an annular outer $\mathrm{Cu}$ stabilizer, 
(ii) Double Barrier (DB) strands, which are indentical to the SB strands except that a second Ta barrier is inserted into the $\mathrm{Cu}$ stabilizer near the strand surface. RRR values of 1900 are found for unplated SB strands, while $\mathrm{Cr}$ plated strands have seriously degraded RRR values of between 50-150. Expected RRR degradation due to $\mathrm{Cr}$ diffusion is calculated for these strands based on literature values of $\mathrm{Cr}$ solubility (S) and diffusivity (D) and are compared to experimental values. $S$ and $D$ values are extracted from the experimental results, and are compared to literature values and to PIXIE measurements on these strands. It is shown that $\mathrm{Cr}$ is responsible for RRR degradation. Measurements on DB strands show better RRR values, ranging from $150-250$ for HT comparable to SB HT.

\section{4: Paper No. 16}

Recovery of Residual Resistance Ratio in Degraded Chromium-Plated $\mathbf{N b}_{3} \mathrm{Sn}$ Strands by Moderate Post-Heat-Treatment Aging

E. W. Collings and M. D. Sumption

Research completed; manuscript planned for 1994.

\section{4: Paper No. 17}

\section{Materials Selection for Ferromagnetic \\ Compensation in Accelerator Magnets \\ E. W. Collings and M. D. Sumption \\ Battelle Memorial Institute, 505 King Ave, Columbus, OH 43201}

Abstract: The magnetic hysteresis loops of $\mathrm{Fe}, \mathrm{Ni}$, and $\mathrm{Ni}-\mathrm{Cu}$ in several geometrical forms were measured at $4.2 \mathrm{~K}$. These materials were then evaluated for possible use as ferromagnetic correction elements in magnets wound from superconductive strands. The influences of demagnetization and cold work on the shape of the hysteresis loop were considered, and the saturation magnetizations, as well as the approach to saturation, were measured. Finally, several schemes were developed which would allow the selected alloys to be used for ferromagnetic compensation.

1994: Paper No. 18

ANOMALOUS MAGNETIC PROPERTIES AND PROXIMITY EFFECT COUPLING IN VAMAS STRANDS

M. D. Sumption and E. W. Collings

Battelle, 505 King Ave., Columbus, OH 43201

ABSTRACT: Anomalously low levels of proximity effect (PE) coupling, as well as an anomalously high paramagnetic tilt, have been found in some of the superconducting multifilamentary strands produced for the Versailles Project on Advanced Materials and Standards (VAMAS). We report on two types strands that were measured for the $2^{\text {nd }}$ VAMAS intercomparison program on low-frequency (hysteretic) AC loss; (i) a Cu matrix (H) series with filament diameters $\left(\mathrm{d}_{\mathrm{f}}\right)$ ranging from $0.5 \mu \mathrm{m}-12 \mu \mathrm{m}$, and (ii) a nominal $\mathrm{Cu}-10$ wt\% Ni (I-) series with $d_{f}$ from $0.4 \mu \mathrm{m}-1 \mu \mathrm{m}$. The I-series strands combined anomalously low levels of PE coupling with a strong paramagnetic tilt. Microprobe analysis of the matrix alloy revealed a composition of $10.3 \mathrm{wt} \% \mathrm{Ni}$ plus $0.78 \mathrm{wt} \% \mathrm{Mn}$, which is in agreement with the manufacturer's specification sheets. The paramagnetic tilt can be shown to be due almost 
entirely to the presence of the Mn which also plays a dominant role in the anomalous PE suppression. On the other hand, manufacturer's specifications and microprobe analysis showed that the matrix for the $\mathrm{H}$-series strands was pure $\mathrm{Cu}$. These strands also exhibited an anomalously low level of PE coupling but for different reasons, to be discussed.

\section{4: Paper No. 19}

\section{CREEP IN ANISOTROPIC MATERIALS*}

\section{M.D. Sumption and E.W. Collings}

Abstract: A model has been developed for creep in materials with anisotropic pinning potentials. This model suggests that the creep for a sample of finite size will have a creep which is some weighted average of the creep along the two principle directions (a 2-D model is used). The weighting depends on the sample dimensions and shape. Specific predictions are made for finite orthorhombic and cylindrical samples, assuming a semi-Bean type field dependence. These predictions are them confirmed on low $T_{c}$ proximity coupled multifilamentary composites. It is found that while creep rate is dependent upon the sample length and the magnetic field, the intrinsic $U_{0}$ of the proximity effected $\mathrm{Cu}$ is $5-10 \mathrm{meV}$. Possible applicability to high $T_{c}$ samples is also discussed. 